\title{
Healthy Living: Keep Track of Your Blood Pressure ${ }^{1}$
}

\author{
Linda B. Bobroff and Leigh Ann Martin ${ }^{2}$
}

Every time you take your blood pressure, write down the date and time, the blood pressure measurement, and where it was taken (home, doctor's office, etc.). Not only that, but include any comments your health care provider made and anything you would like to note, such as how you feel or medications you recently started or stopped.

Talk to your doctor if you have questions about monitoring your blood pressure or hypertension. If you would like to learn more about blood pressure, visit one of these websites:

- http://www.nhlbi.nih.gov/hbp/bp/bp.htm

- http://www.cdc.gov/bloodpressure/

- http://www.strokeassociation.org/STROKEORG/

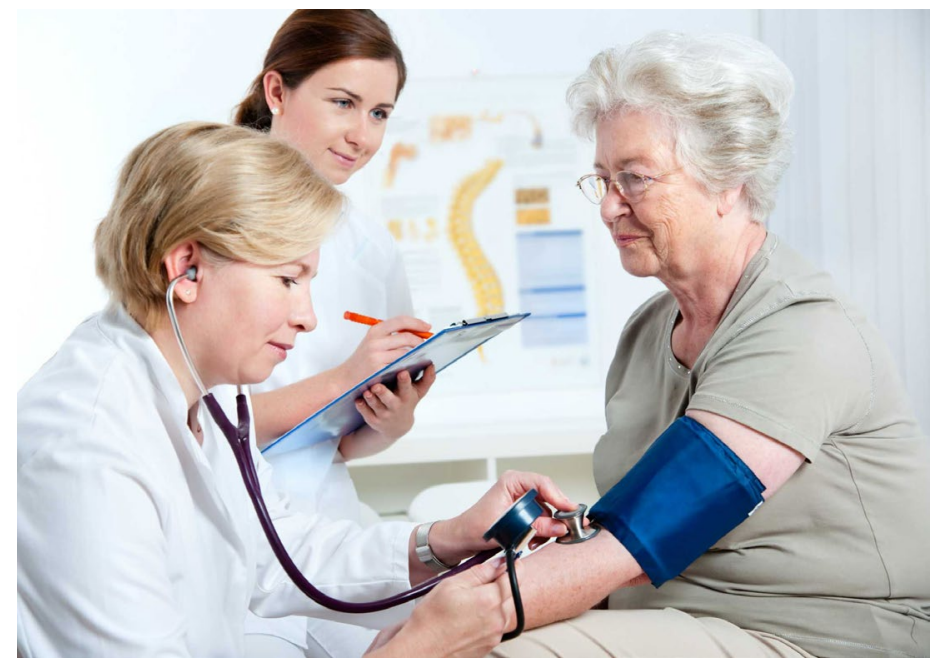

Credits: iStock
While your blood pressure will be checked when you see a health care provider, you can always check your blood pressure at home in between visits.

Checking your blood pressure on a regular basis will help you and your healthcare provider know how well your treatment plan is working.

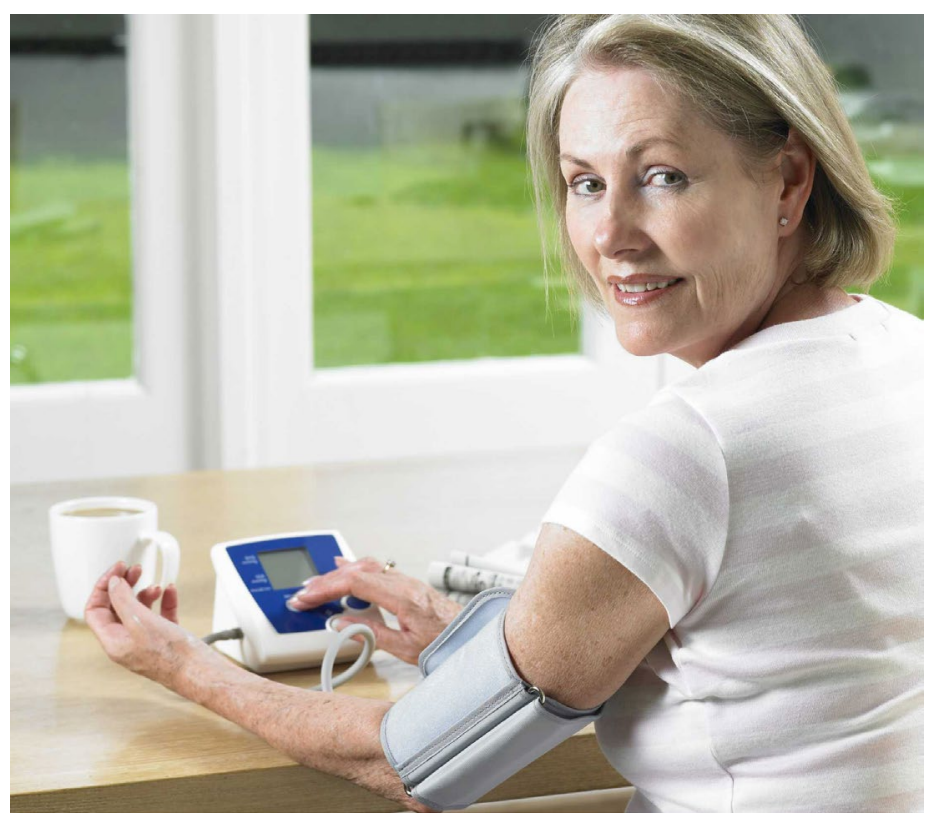

Credits: BananaStock

1. La versión en español de este documento es Vida Saludable: Anote su presión sanguínea (FCS8601Span). This document is FCS8601, one in a series of the Department of Family, Youth and Community Sciences, UF/IFAS Extension, Gainesville, FL 32611. First published: April 2000. Revision: October 2013. Please visit the EDIS website at http://edis.ifas.ufl.edu.

2. Linda B. Bobroff, PhD, RD, LD/N, professor, Leigh Ann Martin, MES., former ENAFS project coordinator, Department of Family, Youth and Community Sciences, UF/IFAS Extension, Gainesville, FL. 
Archival copy: for current recommendations see http://edis.ifas.ufl.edu or your local extension office.

\begin{tabular}{|c|c|c|c|}
\hline Date and Time & Blood Pressure & Place Taken & Comments \\
\hline & 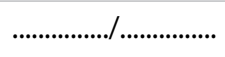 & & \\
\hline & 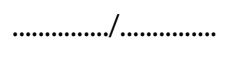 & & \\
\hline & .................................... & & \\
\hline & 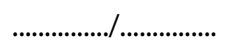 & & \\
\hline & 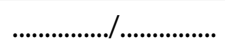 & & \\
\hline & (.................................. & & \\
\hline & 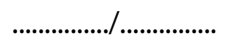 & & \\
\hline & 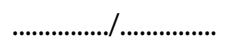 & & \\
\hline & ..................................... & & \\
\hline & 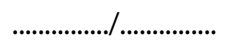 & & \\
\hline & 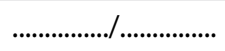 & & \\
\hline & (................................... & & \\
\hline & 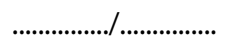 & & \\
\hline
\end{tabular}

